\title{
Do gay and bisexual men who conceal their same-sex behavior prefer different kinds of health services? Findings across four cities to inform client-centered HIV prevention in China
}

Rong Fu', Bryan A. Kutner², Yumeng Wư ${ }^{3}$, Lu Xie ${ }^{4}$, Siyan Meng ${ }^{5}$, Jianhua Hou', Yuzhou Gu', Huifang Xu', Huang Zheng ${ }^{7}, \mathrm{Na} \mathrm{He}^{5}$ and Kathrine Meyers ${ }^{3 *}$

\begin{abstract}
Background: In China, addressing disparities in the HIV epidemic among men who have sex with men (MSM) requires targeted efforts to increase their engagement and retention in prevention. In an effort to advance MSMfriendly HIV services within China, and informed by community-based partnerships, we tested whether MSM who have ever versus never disclosed their same-sex behavior to healthcare providers (HCP) differ in sociodemographic and behavioral characteristics as well as the qualities of sexual health services each group would prefer to access.

Methods: We conducted a cross-sectional survey among HIV-negative MSM who went to MSM-focused voluntary counseling and testing clinics in four cities in China. The survey was anonymous and collected information on sociodemographic characteristics, testing behaviors, sexual-health related behavior, and sexual health service model preferences.

Results: Of 357 respondents, 68.1\% participants had ever disclosed same-sex behavior to HCPs when seeking advice for sexual health. Younger age $(a O R=1.04 ; 95 \% \mathrm{Cl}: 1.01-1.08)$, and worry of HIV acquisition $(a O R=1.39 ; 95 \%$ Cl: 1.05-1.84) were associated with higher odds of past disclosure. The availability of comprehensive sexual health services was one of the most valued characteristics of the ideal sexual health clinic. Those who ever disclosed and never disclosed differed significantly in their ranking of the importance of three out of ten dimensions: sexual health counseling services available $(M=3.99$ vs. $M=3.65, p=.002)$, gay identity support available $(M=3.91$ vs. $M=3.62, p=.016)$ and clinic collaborates with a gay $C B O(M=3.81$ vs. $M=3.56, p=.036)$.

Conclusions: Our hypothesis that MSM who had disclosed versus never disclosed same-sex behavior would differ in the value they placed on different dimensions of sexual health service was partially borne out. As health authorities in China decide on implementation models for pre-exposure prophylaxis (PrEP) delivery and specifically within which institutions to integrate PrEP services, the preferences of target populations should be considered to develop comprehensive, patient-centric and LGBT-friendly services.
\end{abstract}

Keywords: Sexual health service, Healthcare providers (HCPs), Men who have sex with men (MSM), HIV, Sexually transmitted infections (STIs)

\footnotetext{
* Correspondence: kmeyers@adarc.org

${ }^{3}$ Aaron Diamond AIDS Research Center, The Rockefeller University, 455 1st

Avenue, 7th Floor, New York, NY 10016, USA

Full list of author information is available at the end of the article
}

(c) The Author(s). 2020 Open Access This article is distributed under the terms of the Creative Commons Attribution 4.0 International License (http://creativecommons.org/licenses/by/4.0/), which permits unrestricted use, distribution, and reproduction in any medium, provided you give appropriate credit to the original author(s) and the source, provide a link to the Creative Commons license, and indicate if changes were made. The Creative Commons Public Domain Dedication waiver (http://creativecommons.org/publicdomain/zero/1.0/) applies to the data made available in this article, unless otherwise stated. 


\section{Background}

In many areas of the world where homosexuality remains illegal or stigmatized in structural and social ways, gay, bisexual and other men who have sex with men (MSM) largely decline to disclose their sexuality and same-sex behavior to healthcare providers (HCPs) [1]. This concealment protects MSM against the deleterious effects of experiencing further maltreatment [2], but also means that HCPs miss opportunities to tailor sexual health services to intervene on the disproportionate burden of STIs and HIV experienced by MSM as a key population [3]. While environmental factors in healthcare settings, such as HCPs' negative attitudes and verbal harassment of MSM, may limit men's willingness to disclose same-sex behavior [2], at least some of these factors are amenable to change [3]. For example, broadening the focus from HIV to sexual health and including mental health services related to sexuality might lead to improved engagement of MSM across the HIV continuum [4].

In China, over the course of the rapid expansion of a nationwide epidemic of HIV and STIs during the past two decades, MSM are now recognized as a disproportionately affected group $[5,6]$. In the past ten years, Chinese funding bodies have scaled up HIV testing services for MSM in both healthcare settings and CBOs [5]. However, delayed and suboptimal HIV and syphilis testing and ART initiation remain common [7-9]. A very high proportion of Chinese MSM also experience stigma in healthcare settings and do not disclose sexual orientation to their health professionals [10, 11]. Reorienting existing health services to affirm MSM sexuality, in line with the World Health Organization (WHO) definition of sexual health [12] and recommendations for sexual health service models specific to MSM [3, 13] may lessen the disproportionate burden of HIV and STIs by improving engagement and retention in services [14].

Previous studies have evaluated sexual health services by focusing on HCPs' perception of MSM [13] and MSM disclosure in the context of healthcare discrimination [11]. While most Chinese MSM prefer to go to MSM-focused CBOs for HIV counselling and testing $[15,16]$, little is known about how these men seek HIV testing services in this high stigma setting or perceive sexual health services. In this study, we aimed to assess two aspects of sexual health services: A) demographic and behavioral characteristics associated with disclosure of same-sex behavior to HCPs, and B) whether disclosure was associated with different priorities for sexual health services among MSM.

\section{Methods}

\section{Study design and sampling methods}

Our study team held a series of stakeholder meetings in China with gay community leaders, HIV prevention intervention staff at municipal Centers for Disease Control and Prevention (CDC), and antiretroviral and STI clinic providers to discuss potential models for sexual health services for Chinese MSM. Importantly, stakeholders posited that MSM who conceal their same-sex behavior may differ in the qualities they prioritize within sexual health services that they would like to access, compared to counterparts who have already disclosed their same-sex behavior within a health care setting.

To test this hypothesis, between February and May 2018, we conducted a cross-sectional study in four cities (Shanghai, Beijing, Changsha, and Guangzhou) in a convenience sample of Chinese MSM. Staff at gay-oriented CBOs recruited participants through four methods: voluntary counselling and testing (VCT) clinics with posters, peer networks, outreach at gay venues with fliers, and online through CBOs' WeChat posts. Four trained research coordinators (RF, LX, JH, and SM) assessed eligibility criteria and screened men who identified as: 18 years or older, assigned male at birth, had ever engaged in sex with another man, and HIV-negative by self-report.

Computer-based surveys were administered in person by either $\mathrm{CBO}$ staff or research coordinators or selfadministered by participants themselves. Participants gave written informed consent prior to survey administration and received compensation of $\$ 7.40$ USD or equivalent condom and lubricant as compensation for their time. Recruitment halted after reaching the pre-specified sample of 700, of whom 362 were recruited through VCT clinic. We restricted the sample to VCT-recruited participants for this research question. Protocol and all study procedures were approved by the ethics review committee of Fudan University (Shanghai, China).

\section{Measures}

The survey was anonymous and collected information on sociodemographic characteristics and sexual health related behavior, including testing behaviors, sexual risk and risk perception, and preferences for dimensions of a sexual health service model. Most survey items were adapted from an existing assessment instrument for Chinese MSM [17].

The outcome measure was lifetime disclosure of samesex behavior to HCPs when seeking advice for sexual health issues. This advice-seeking could relate to bleeding, pain, itching, infections in genital or anal areas, or sexual dysfunction.

Sociodemographic information included age, city currently living in, residence (local or non-local), education, employment status, student status, household composition, marital status, and average monthly income (low and middle income, middle income, and high income) [18]. 
We collected detailed information on sexual health related behavior. Participants self-reported if they ever had a sexual health issue that interfered with sex (yes or no) as well as ever experienced sexual health issues and went to see HCPs (yes or no). We broadly defined HCPs based on classification from WHO [19] and MSMspecific guidelines [4], as either health professionals, or lay HIV counselors. The survey also asked participants about their frequency of HIV and STI testing and sexual risk behavior. Variables associated with sexual risk behavior within the past 6 months included number of male sex partners, HIV-positive male partner, condomless anal sex, commercial sex behavior with male sex partners, STI symptoms/diagnosis, recreational drug use, sexual positioning, and group sex with male sex partners. We assessed self-perception of HIV risk with the following questions: "In five years, how likely do you think you are to become infected with HIV" (ranging from 1 very unlikely to 4 very likely); "In the past two years, have any of your friends or people you know become infected with HIV" (no, yes, I don't know); and "How worried are you of becoming infected with HIV" (ranging from 1 not worried at all to 4 very worried).

After iterative discussions with GPP stakeholders in four participating cities, we developed an MSM-specific sexual health service model that participants could evaluate by prioritizing the model's hypothetical "ideal" dimensions. Participants ranked the relative importance of each dimension of this clinic-based sexual health service model using a 5-point Likert scale (ranging from 1 not at all important to 5 extremely important). The model comprised ten dimensions (e.g., positive reputation in lesbian, gay, bisexual, transgender [LGBT] community, services are available anonymously, clinic is not LGBT-specific; see Table 2).

\section{Statistical analysis}

To answer our research question about differences by concealment of same-sex behavior, we stratified descriptive statistics for socio-demographics, testing behaviors, sexual behaviors, risk perceptions, and the sexual health service model by whether participants had disclosed same-sex behavior to an HCP at least once in their lives when seeking advice for sexual health issues (disclosure vs. non-disclosure). For our first aim to assess factors associated with disclosure vs. non-disclosure, we performed bivariate analyses using $\mathrm{T}$ tests and chi-square tests to evaluate the difference between the two groups on socio-demographic and sexual health related behavior. Significant variables were then analyzed in multivariate logistic regression (odds ratios, 95\% confidence intervals) to evaluate independent factors associated with disclosing same-sex behavior to HCPs. Variables with $p$ values $<.10$ in bivariate analyses were selected for inclusion in an initial logistic regression model and odds ratios with $p$-values $<.05$ were included in the final multivariate model. We calculated mean scores for each dimension and across all 10 dimensions of sexual health service and likewise stratified by disclosure for bivariate analyses. All data analyses were completed using IBM SPSS Statistics 20 (IBM, Armonk, NY, USA).

\section{Results}

Of 362 respondents, 1.4\% $(n=5)$ of respondents had missing data. Of the 357 respondents in the final sample, $68.1 \%(n=243)$ had disclosed same-sex behavior to an $\mathrm{HCP}$ at least once in their lives when seeking advice for sexual health issues (Table 1).

\section{Socio-demographics}

As seen in Table 1, participants ranged from 18 to 85 years old $(M=31.5, S D=9.4)$. Overall, two-thirds of participants self-identified as gay and about a third as bisexual. Just over two-thirds reported a college degree or higher. Most were not married, and most were employed full-time. Nearly half reported high-income.

\section{Sexual health related behavior}

About one in ten had never tested for HIV and nearly one in three had never tested for an STI. More than half reported receptive anal sex in the past 6 months, and many were unaware of the HIV status of their partner(s). On average, participants thought they were unlikely to become infected with HIV in the next five years and endorsed worry about acquiring HIV. About two-fifths knew someone who had acquired HIV in the last two years.

Three quarters reported seeing an HCP for a sexual health issues that had interfered with sex. Of these, most had disclosed same-sex behavior to an HCP at least once in their lives while seeking sexual health services. Among those who avoided seeking care for such an issue, half cited the main barrier to be fear of stigma toward same-sex behavior by HCPs (Fig. 1).

\section{Demographic differences by disclosure of same-sex behavior to HCPs}

Those who had ever sought help for sexual health and disclosed same-sex behavior to their HCPs were significantly more likely, at $p<.10$, to report younger age, living with other people, not having a local residency permit, more frequent HIV testing and STI testing, greater worry about HIV acquisition, more receptive anal penetration, and differences by city of residence as compared to those MSM who had never disclosed (Table 1). We did not find evidence that disclosure of same-sex behavior to HCPs was associated with any other sociodemographic variables. 
Table 1 Socio-demographic and behavioral characteristics of Chinese MSM, stratified by history of disclosure of same-sex behavior to HCP when seeking sexual health services $(N=357)$

\begin{tabular}{llll}
\hline Ever & Never & $p$ & Overall \\
disclosed & disclosed & & $(N=357)$ \\
$n(\%)$ & $n(\%)$ & \\
$243(68.1)$ & $114(31.9)$ & \\
\hline
\end{tabular}

Socio-demographics

Age $(M, S D)$

$30.6,9.2 \quad 33.4,9.6 \quad 0.009 \quad 31.5,9.4$

City currently living in

Shanghai

Beijing

Changsha

Guangzhou

Local residency permit

College education or above

Full-time employment

(20 missing data)

Household

I live by myself

\begin{tabular}{|c|c|c|c|}
\hline $75(60.0)$ & $50(40.0)$ & 0.009 & 125 \\
\hline $56(64.4)$ & 31 (35.6) & & 87 \\
\hline $74(81.3)$ & 17 (18.7) & & 91 \\
\hline $36(66.7)$ & 18 (33.3) & & 54 \\
\hline
\end{tabular}

Married

$40(66.7) \quad 20(33.3) \quad 0.879 \quad 60$

Average monthly income (USD)

Low and middle income $(\leq 442)$

Middle income

(443-1474)

High income ( $\geq 1474)$

$33(82.5) \quad 7(17.5) \quad<0.001 \quad 40$

$79(77.5) \quad 23(22.5) \quad 102$

$47(74.6) \quad 16(25.4)$

63

$84(55.3) \quad 68(44.7) \quad 152$

$71(64.5) \quad 39(35.5) \quad 0.390 \quad 110$

0.811238

$158(65.0) \quad 85(35.0) \quad 0.505 \quad 243$

$41(74.5) \quad 14(25.5) \quad 0.350 \quad 55$

$94(69.6) \quad 41(30.4) \quad 135$

$108(64.7) \quad 59(35.3)$

Sexuality

Sexual attraction

More to women than to men/Only to women

To women and men equally

More to men than to women

Only to men

$\begin{array}{llll}7(58.3) & 5(41.7) & 0.732 & 12 \\ 27(62.8) & 16(37.2) & 43 \\ 108(69.7) & 47(30.3) & 155 \\ 101(68.7) & 46(31.3) & 147\end{array}$

Sexual identity

Bisexual
Gay
Heterosexual/Other
Current intimate sexual
relationship with a woman
sting behaviors
Frequency of HIV testing
Never$$
74(66.7) \quad 37(33.3) \quad 0.896 \quad 111
$$$$
166 \text { (68.6) } 76(31.4)
$$$$
3(75.0) \quad 1(25.0)
$$$$
38(61.3) \quad 24(38.7)
$$$$
\text { Testing behaviors }
$$$$
\text { Never }
$$$$
18(42.9) \quad 24(57.1)
$$

0.896111
Table 1 Socio-demographic and behavioral characteristics of Chinese MSM, stratified by history of disclosure of same-sex behavior to HCP when seeking sexual health services $(N=357)$ (Continued)

\begin{tabular}{|c|c|c|c|c|}
\hline & $\begin{array}{l}\text { Ever } \\
\text { disclosed } \\
n(\%) \\
243(68.1)\end{array}$ & $\begin{array}{l}\text { Never } \\
\text { disclosed } \\
n(\%) \\
114(31.9)\end{array}$ & $p$ & $\begin{array}{l}\text { Overall } \\
(N=357)\end{array}$ \\
\hline Once per year or less & $70(65.4)$ & $37(34.6)$ & & 107 \\
\hline $\begin{array}{l}\text { About 2-3 times per } \\
\text { year }\end{array}$ & $80(73.4)$ & $29(26.6)$ & & 109 \\
\hline At least 4 times per year & $75(75.8)$ & $24(24.2)$ & & 99 \\
\hline \multicolumn{5}{|l|}{ Frequency of STI testing } \\
\hline Never & $63(60.6)$ & $41(39.4)$ & 0.028 & 104 \\
\hline Once per year or less & $90(65.2)$ & $48(34.8)$ & & 138 \\
\hline $\begin{array}{l}\text { About 2-3 times per } \\
\text { year }\end{array}$ & $47(75.8)$ & $15(24.2)$ & & 62 \\
\hline At least 4 times per year & $43(81.1)$ & $10(18.9)$ & & 53 \\
\hline
\end{tabular}

Sexual behavior in past 6 months

Anal sex positioning (15 missing data)

$$
\begin{array}{lllll}
\text { Any receptive } & 154(73.3) & 56(26.7) & 0.009 & 210 \\
\text { Insertive only } & 78(59.1) & 54(40.9) & 132
\end{array}
$$

\begin{tabular}{|c|c|c|c|c|}
\hline Only with men & $172(69.4)$ & $76(30.6)$ & \multirow[t]{2}{*}{0.664} & 248 \\
\hline $\begin{array}{l}\text { More with men than } \\
\text { with women }\end{array}$ & $36(63.2)$ & $21(36.8)$ & & 57 \\
\hline $\begin{array}{l}\text { With women and } \\
\text { men equally }\end{array}$ & $9(56.2)$ & $7(43.8)$ & & 16 \\
\hline $\begin{array}{l}\text { More with women } \\
\text { than with men/Only } \\
\text { with women }\end{array}$ & $8(66.7)$ & $4(33.3)$ & & 12 \\
\hline Haven't had sex & $33(78.6)$ & $9(21.4)$ & & 24 \\
\hline \multicolumn{5}{|c|}{ Number of male sex partners } \\
\hline $0-1$ & $102(66.7)$ & $51(33.3)$ & \multirow[t]{3}{*}{0.140} & 153 \\
\hline $2-5$ & $118(66.7)$ & $59(33.3)$ & & 177 \\
\hline$\geq 6$ & $23(85.2)$ & $4(14.8)$ & & 27 \\
\hline
\end{tabular}

Sex with men or women or both

HIV-positive male sex partner (15 missing data)

$$
\text { None }
$$$$
116(66.7) \quad 58(33.3) \quad 0.393 \quad 174
$$

I don't know $105(69.5) \quad 46(30.5)$

Yes, partner on ART $8(80.0) \quad 2(20.0)$

Yes, partner not on ART

$3(42.9) \quad 4(57.1)$

Condomless anal sex $106(72.6) \quad 40(27.4)$

$0.128 \quad 146$

Commercial sex with $18(66.7) \quad 9(33.3)$

$1.000 \quad 27$ male sex partners

$\begin{array}{lllll}\text { STI symptoms /diagnosis } & 17(73.9) & 6(26.1) & 0.647 & 23 \\ \text { Recreational drug use } & 3(75.0) & 1(25.0) & 1.000 & 4 \\ \text { Group sex with } & 27(71.1) & 11(28.9) & 0.716 & 38\end{array}$
male sex partners 
Table 1 Socio-demographic and behavioral characteristics of Chinese MSM, stratified by history of disclosure of same-sex behavior to HCP when seeking sexual health services $(N=357)$ (Continued)

\begin{tabular}{lllll}
\hline & $\begin{array}{l}\text { Ever } \\
\text { disclosed } \\
n(\%) \\
243(68.1)\end{array}$ & $\begin{array}{l}\text { Never } \\
\text { disclosed } \\
n(\%)\end{array}$ & $p$ & $\begin{array}{l}\text { Overall } \\
(N=357)\end{array}$ \\
& & & & \\
\hline $\begin{array}{l}\text { Perceptions of HIV and risk } \\
\text { HIV in social networks }\end{array}$ & $92(66.7)$ & $46(33.3)$ & 0.812 & 138 \\
$\begin{array}{l}\text { Likelihood of HIV } \\
\text { acquisition (M, SD) }\end{array}$ & $2.1,0.7$ & $2.2,0.7$ & 0.157 & $2.1,0.7$ \\
$\begin{array}{l}\text { Worry about HIV } \\
\text { acquisition (M, SD) }\end{array}$ & $3.1,0.9$ & $2.8,0.9$ & 0.003 & $3.0,0.9$ \\
\hline
\end{tabular}

Factors independently associated with disclosure of same-sex behavior to HCPs

In a multivariate model of factors significant in bivariate analyses, MSM who were older $(a O R=.96$; 95\% CI: .93-.99) and those who reported insertive sex only $(a O R=.47 ; 95 \% C I: .28-.78)$ had significantly lower odds of having disclosed same-sex behavior to their HCPs. Those who stated that they were afraid of contracting $\mathrm{HIV}(a O R=1.39$; 95\% CI: 1.05-1.84) had higher odds of having disclosed (Table 2).
Sexual health services MSM value by disclosure of samesex behavior to HCPs

The overall average importance score for all dimensions of the "ideal" sexual health clinic was $M=3.73(S D=.23)$ and ranged from 3.34 to 4.01 on the 5-point Likert scale (Table 3). Ever disclosed respondents had higher scores than never disclosed respondents, with no significant mean differences for the overall model $(M=3.80$ vs. $M=3.60, p=.07)$. However, the two groups differed significantly across three dimensions (in order of magnitude): sexual health counseling services available $(M=3.99$ vs. $M=3.65, p=.002)$, gay identity support available $(M=3.91$ vs. $M=3.62, p=.016)$, and clinic collaborates with a gay $C B O(M=3.81$ vs. $M=3.56$, $p=.036)$. Both groups valued positive reputation in the LGBT community and comprehensive sexual health services available as the top two services. The largest gap in ranking, albeit not statistically significant by mean differences, was services are available anonymously, ranked 5th in the disclosure group versus 3rd in the non-disclosure group $(M=3.88$ vs. $M=3.67, p=.081)$. Healthcare providers are aware of clients' same-sex behavior and LGBT staff ranked as the bottom two services in importance for both groups (Fig. 2).

\section{Discussion}

We examined whether disclosure of same-sex behavior to HCPs was associated with demographic and

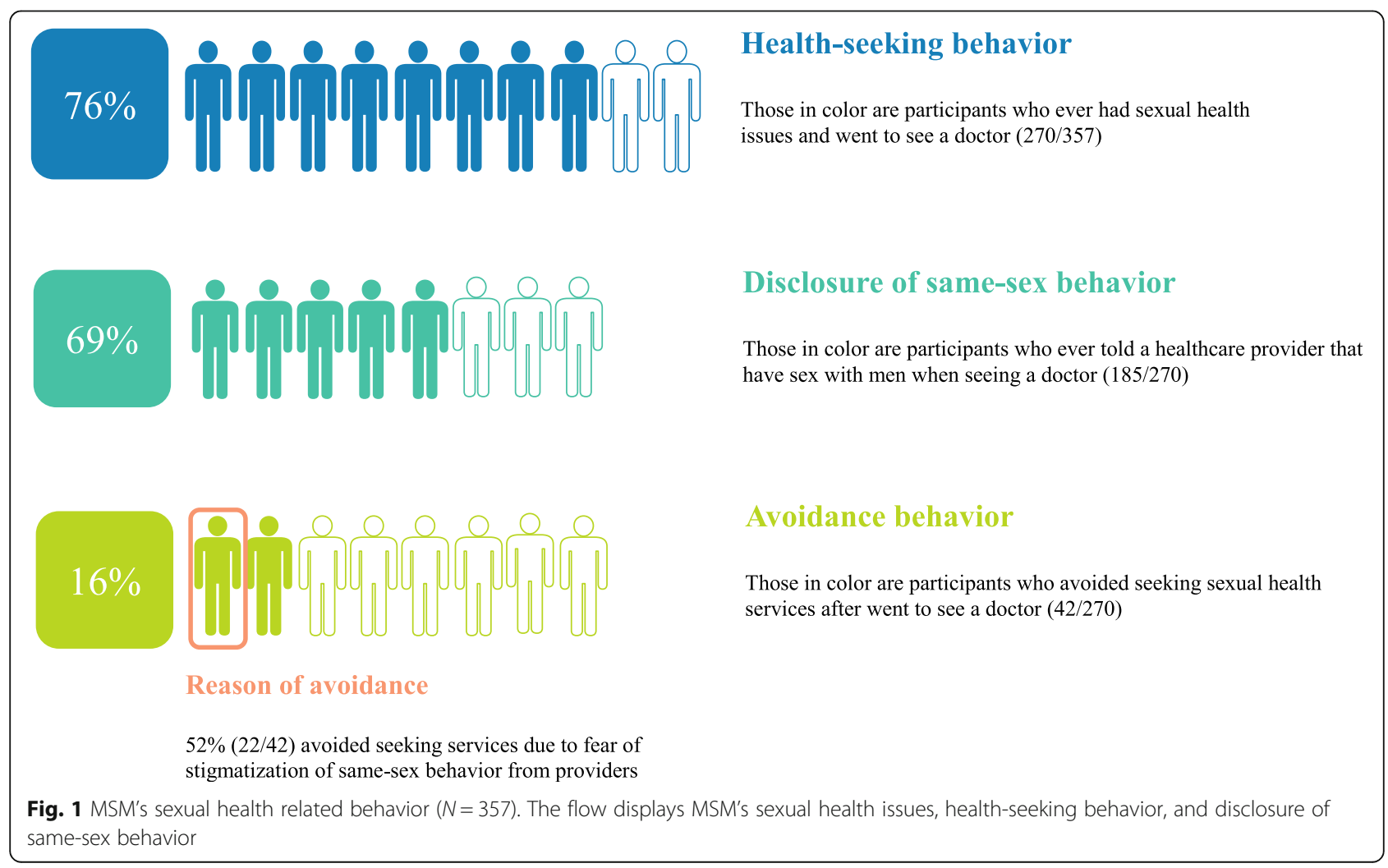


Table 2 Factors associated with disclosure of same-sex behavior to HCP $(N=357)$

\begin{tabular}{|c|c|c|c|c|}
\hline & Crude OR (95\% Cl) & $P$ & Adjusted OR (95\% Cl) ${ }^{*}$ & $P$ \\
\hline \multicolumn{5}{|l|}{ Socio-demographics } \\
\hline Age (in years) & $0.97(0.95-0.99)$ & 0.010 & $0.96(0.93-0.99)$ & 0.005 \\
\hline \multicolumn{5}{|l|}{ City currently living in } \\
\hline Shanghai & 1 & & & \\
\hline Beijing & $0.73(0.29-1.86)$ & 0.508 & & \\
\hline Changsha & $0.62(0.23-1.68)$ & 0.351 & & \\
\hline Guangzhou & $0.26(0.11-0.63)$ & 0.003 & & \\
\hline \multicolumn{5}{|l|}{ Household } \\
\hline I live by myself & 1 & & 1 & \\
\hline I live with a partner & $1.20(0.68-2.12)$ & 0.520 & $1.00(0.52-1.90)$ & 0.991 \\
\hline I live with roommate(s) or relatives & $2.09(1.54-5.49)$ & 0.001 & $1.79(0.84-3.79)$ & 0.130 \\
\hline I do not have a stable home/Other & $1.50(0.75-2.99)$ & 0.249 & $1.18(0.54-2.61)$ & 0.678 \\
\hline \multicolumn{5}{|l|}{ Testing behaviors } \\
\hline \multicolumn{5}{|l|}{ Frequency of HIV testing } \\
\hline Never & 1 & & 1 & \\
\hline Once per year or less & $2.52(1.22-5.23)$ & 0.013 & $2.16(0.85-5.49)$ & 0.108 \\
\hline About 2-3 times per year (every 4-6 months) & $3.68(1.75-7.74)$ & 0.001 & $2.67(0.99-7.22)$ & 0.053 \\
\hline At least 4 times per year (every 3 months) & $4.17(1.94-8.95)$ & $<0.001$ & $1.82(0.62-5.35)$ & 0.275 \\
\hline \multicolumn{5}{|l|}{ Frequency of STI testing } \\
\hline Never & 1 & & 1 & \\
\hline Once per year or less & $1.22(0.72-2.07)$ & 0.459 & $1.23(0.60-2.51)$ & 0.572 \\
\hline About 2-3 times per year (every 4-6 months) & $2.04(1.01-4.11)$ & 0.047 & $1.13(0.44-2.89)$ & 0.801 \\
\hline At least 4 times per year (every 3 months) & $2.80(1.27-6.18)$ & 0.011 & $2.77(0.90-8.51)$ & 0.075 \\
\hline \multicolumn{5}{|l|}{ Sex risk in past 6 months } \\
\hline \multicolumn{5}{|l|}{ Sex role } \\
\hline Any receptive " 0 " or " 0.5 " & 1 & & 1 & \\
\hline Insertive "1" only & $0.53(0.33-0.83)$ & 0.006 & $0.47(0.28-0.78)$ & 0.004 \\
\hline Worry about HIV acquisition (vs. not worried) & $1.43(1.13-1.81)$ & 0.003 & $1.39(1.05-1.84)$ & 0.020 \\
\hline
\end{tabular}

sexual health factors among MSM who visited gayoriented CBOs for HIV VCT services in four cities in China, and relatedly, whether their past disclosure while seeking sexual health services was associated with their preferences for hypothetical sexual health services. Overall in our sample, MSM reported a high prevalence of sexual health issues, elevated worry about becoming infected with HIV, and extraordinarily high proportions of seroconversions within their social networks. In multivariate logistic regression, MSM who reported younger age and greater worry about HIV acquisition were more likely to have disclosed their same-sex behavior to HCPs. Past disclosure was also associated with slightly greater interest in three out of ten dimensions for sexual health services.
Disclosure of same-sex behavior to HCPs and testing and sexual behaviors of MSM

A large majority (68.1\%) of respondents reported that they had previously experienced a sexual health issue that interfered with their sex life, sought care, and disclosed their same-sex behavior to an HCP, highlighting the importance of understanding the sexual health of sexual-minority populations beyond the narrow lens of HIV. This high prevalence of disclosure is close to those reported in a recent systematic review [2] with a median of $61 \%$ across 15 studies. However, this review was largely conducted in high-income countries. Compared to a 2014 nationwide online study [11] in China, in which only $16 \%$ MSM reported disclosure of their sexual orientation to HCPs, our prevalence of disclosure is much higher. We attribute the difference to recruitment 
Table 3 Sexual healthcare delivery model stratified by history of disclosure of same-sex behavior to HCP $(N=357)$

\begin{tabular}{|c|c|c|c|c|c|c|c|}
\hline & \multicolumn{2}{|l|}{$\begin{array}{l}\text { Ever disclosed } \\
n(\%) \\
243(68.1)\end{array}$} & \multicolumn{2}{|l|}{$\begin{array}{l}\text { Never disclosed } \\
n(\%) \\
114(31.9)\end{array}$} & \multirow[b]{2}{*}{$\begin{array}{l}\text { t-test } \\
\text { score }(p)\end{array}$} & \multicolumn{2}{|l|}{ Overall $(N=357)$} \\
\hline & $\begin{array}{l}\text { Importance score } \\
(M, S D)\end{array}$ & $\begin{array}{l}\text { Ranking } \\
(1-10)\end{array}$ & $\begin{array}{l}\text { Importance score } \\
(M, S D)\end{array}$ & $\begin{array}{l}\text { Ranking } \\
(1-10)\end{array}$ & & $\begin{array}{l}\text { Importance score } \\
(M, S D)\end{array}$ & $\begin{array}{l}\text { Ranking } \\
(1-10)\end{array}$ \\
\hline Positive reputation in LGBT community & $4.06,1.00$ & 1 & $3.89,0.95$ & 2 & $\begin{array}{l}-1.49 \\
(0.138)\end{array}$ & $4.01,0.99$ & 2 \\
\hline $\begin{array}{l}\text { Comprehensive sexual health services } \\
\text { available }\end{array}$ & $4.05,0.92$ & 2 & $3.95,0.98$ & 1 & $\begin{array}{l}-1.00 \\
(0.319)\end{array}$ & $4.02,0.94$ & 1 \\
\hline $\begin{array}{l}\text { Sexual health counseling services } \\
\text { available }\end{array}$ & $3.99,0.91$ & 3 & $3.65,1.08$ & 4 & $\begin{array}{l}-3.12 \\
(0.002)\end{array}$ & $3.88,0.98$ & 3 \\
\hline Gay identity support available & $3.91,1.04$ & 4 & $3.62,1.05$ & 5 & $\begin{array}{l}-2.42 \\
(0.016)\end{array}$ & $3.82,1.05$ & 4 \\
\hline Services are available anonymously & $3.88,1.02$ & 5 & $3.67,1.13$ & 3 & $\begin{array}{l}-1.75 \\
(0.081)\end{array}$ & $3.81,1.06$ & 5 \\
\hline Clinic collaborates with a gay CBO & $3.81,0.99$ & 6.5 & $3.56,1.09$ & 7 & $\begin{array}{l}-2.11 \\
(0.036)\end{array}$ & $3.73,1.03$ & 7 \\
\hline Positive reputation for HIV services & $3.81,1.03$ & 6.5 & $3.61,1.16$ & 6 & $\begin{array}{l}-1.72 \\
(0.086)\end{array}$ & $3.75,1.08$ & 6 \\
\hline Clinic is NOT LGBT-specific & $3.63,1.05$ & 8 & $3.47,1.00$ & 8 & $\begin{array}{l}-1.37 \\
(0.172)\end{array}$ & $3.58,1.03$ & 8 \\
\hline LGBT staff & $3.45,1.13$ & 9 & $3.35,1.03$ & 9 & $\begin{array}{l}-0.82 \\
(0.415)\end{array}$ & $3.42,1.10$ & 9 \\
\hline $\begin{array}{l}\text { Healthcare providers are aware of clients' } \\
\text { same-sex behavior }\end{array}$ & $3.40,1.16$ & 10 & $3.22,1.03$ & 10 & $\begin{array}{l}-1.45 \\
(0.149)\end{array}$ & $3.34,1.12$ & 10 \\
\hline
\end{tabular}

*1 $=$ Not at all important, $5=$ Extremely important

within gay-oriented $\mathrm{CBOs}$, an indication that gay-specific services may be associated with greater disclosure. However, while most men who experience a sexual health issue sought care and most disclosed their same sex behavior to providers, half of those who did not seek healthcare cited anticipated stigma by $\mathrm{HCPs}$ as the primary reason for not doing so, suggesting continued need for interventions that build the capacity of HCPs to deliver MSM-competent care. This finding is generally in line with the findings

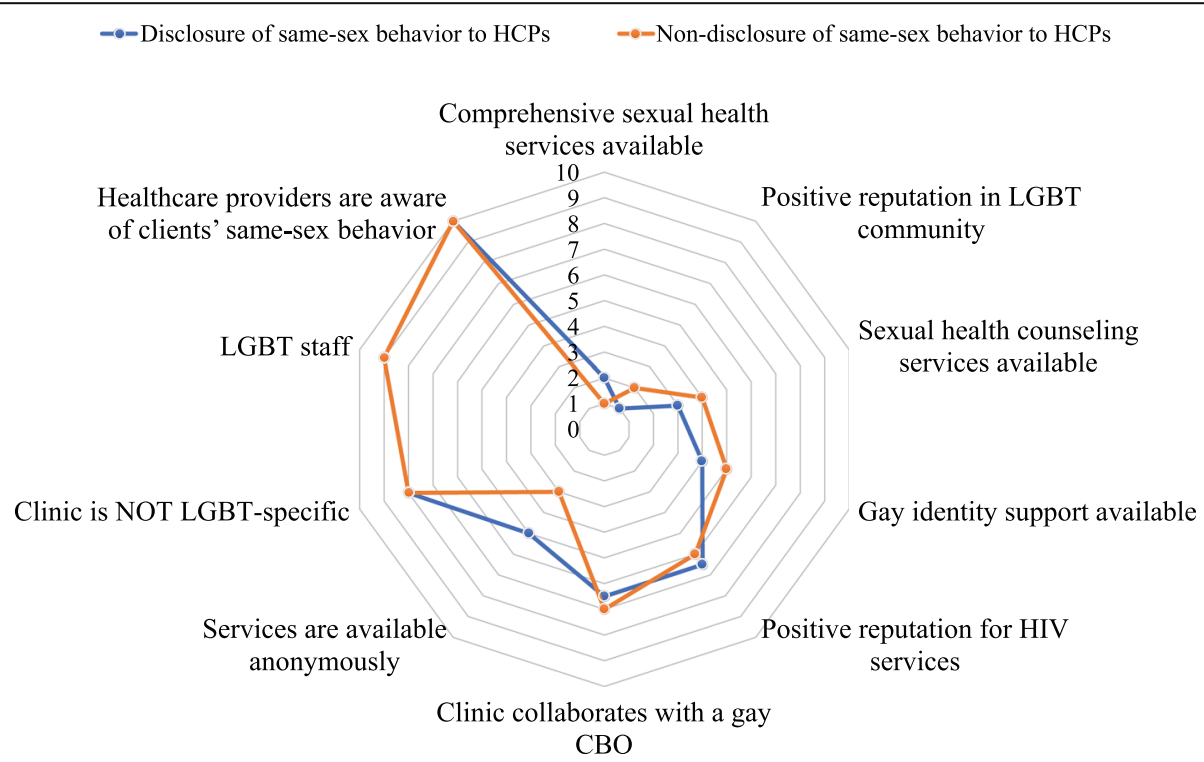

Fig. 2 Dimensions of sexual healthcare services that gay men value grouped by disclosure of same-sex behavior to HCP $(N=357)$. The spider map presents sexual health services that MSM valued when seeing HCPs 
from a 2017 study that three-fifths of MSM who saw a physician in the last two years in China have ever experienced healthcare discrimination [10].

Though all participants were recruited from MSMfocused VCT clinics, a sizable minority (11.8\%) reported never having tested for HIV. In China, MSM-focused CBOs may function as a place for social support related to sexual health, such as counselling related to sexual orientation or obsessive fear about HIV acquisition, rather than solely HIV testing. These participants may also have visited the VCT clinic for the first time, and remained precontemplative or contemplative about HIV testing itself. Further research could better describe this important subpopulation, to better understand the connection between never testing for HIV and visiting MSM-focused CBOs.

\section{Ideal sexual health clinic for MSM}

Those men who ever disclosed same-sex behavior placed a higher value on sexual health counseling services, support for gay identity, and gay $\mathrm{CBO}$ oriented clinic than those never who had never disclosed. In the context of previous studies of disclosure and HIV/STI services among MSM [11, 14, 15, 20] our sexual health service model highlighted the importance of cultural and psychological supports in sexual health services. Disclosure of same-sex behavior by MSM to HCPs is integral to appropriate sexual health services, (e.g. HPV vaccination) and likely depends on provider-level interactions [21,22].

The availability of comprehensive sexual health services was the most valued dimension in our sample. A "one-stop shopping" approach, clustering a variety of tailored sexual health services for MSM in the same venue $[23,24]$, have yet to be provided in the Chinese context $[10,25]$. It will be critical to identify models that integrate sexual health services with HIV prevention with the upcoming introduction of HIV pre-exposure prophylaxis (PrEP) into China for key populations such as MSM [26]. However, there are structural barriers to achieving this. One example is that primary care physicians, whose services are underused since most people see specialists first, may be more competent in managing health services or facilitating referrals for MSM clients [10]. Other barriers stem from STI specialists. Though WHO has recommended provider-initiated HIV testing and counseling since 2007 [27], and HIV testing rates in STI clinics have steadily increased [28], low perception of the prevalence of disease is still common among STI care providers [13]. These STI specialists may experience difficulties in recognizing their MSM clients' needs and providing competent services.

The largest gap in the service dimensions related to anonymity. Not surprisingly, those who had not previously disclosed same-sex behavior prized service dimensions that connote less risk of disclosure. Compared to MSM who had disclosed, they reported slightly lower preferences for sexual health counseling, gay identity support, reputation for HIV services, collaboration with a gay CBO, and awareness among HCPs of clients' same sex behavior. While anonymity distinguished the two groups, HCPs being aware of clients' same-sex behavior (ranked 10th in both groups) was the least valued service for all. Substantial discrimination and stigma toward same-sex behavior in healthcare settings could be a key reason why most MSM prefer to avoid disclosing same-sex behavior when going to HCPs for sexual health issues [10]. A few studies have shown that ignorance of LGBT lifestyles and sexual practices, lack of appropriate language and probing, preconception of MSM clients' sexual orientation, and homophobic attitudes from HCPs are key barriers to disclosure $[2,25]$. Structural intervention and training for HCPs can be effective strategies to facilitate disclosure of same-sex behaviors in MSM, which could ultimately resolve the gaps between the demand for sexual health services and the delivery of sexual health services [2,3].

Our study has several limitations. First, we investigated disclosure of same-sex behavior and sexual health service model based on client-side perceptions and did not incorporate HCPs' perspectives. Second, recall bias may limit how participants answered questions related to health-seeking experiences. Third, the participants were recruited from an HIV VCT clinic, which might introduce selection bias, as CBOs in these four cities in China include MSM-friendly staff. Fourth, this was a crosssectional study and no causal relationships can be inferred.

\section{Conclusions}

Our hypothesis that MSM who had disclosed versus never disclosed same-sex behavior would differ in the value they placed on different dimensions of sexual health services was partially borne out. A cross-sectional survey to elicit opinions and preferences on service delivery dimensions of more hidden MSM populations, who likely have much lower rates of disclosure to HCP, could be conducted through online recruitment methods and bring more nuance to our understanding of diversity within MSM populations in China. As health authorities in China decide on implementation models for PrEP delivery and, specifically how to integrate PrEP into existing health services, attention should be paid to the preferences of target populations in order to develop comprehensive, patient-centric and LGBT-friendly services. Well-designed pragmatic trials to compare service delivery models of PrEP could be helpful to inform introduction and scale up of PrEP so that this powerful biomedical intervention can be delivered in a way that maximizes its potential to rapidly achieve epidemiological impact. 


\section{Abbreviations}

CBO: Community-based Organization; GPP: Good Participatory Practices; HCPs: Healthcare Providers; HIV: Human Immunodeficiency Virus; LGBT: Lesbian, Gay, Bisexual, Transgender; MSM : Men Who Have Sex with Men; PrEP : Pre-exposure Prophylaxis; STIs: Sexually Transmitted Infections; VCT : Voluntary Counselling and Testing

\section{Acknowledgements}

This study was supported by the Good Participatory Practices (GPP) program of Aaron Diamond AIDS Research Center. The authors would like to thank all the GPP team members and collaborators: Weibin Cheng (Guangzhou Center for Disease Control and Prevention, China; Dermatology Hospital of Southern Medical University, China), Xiaojie Huang (Beijing You'an Hospital, China), Min Wang (First Hospital of Changsha, China) and the following community-based organizations: Changsha Zonda-sunshine Social Work Center, QingCai Volunteer Center, Lingnan Partners, Zhitong, Tianyuan. We thank all our participants for their responses and their time.

\section{Authors' contributions}

$\mathrm{KM}, \mathrm{NH}$, and YW conceived of the study; RF, LX, JH, SM, and HZ contributed to the conduct of the survey; RF performed the statistical analyses; $Y G, H X$, $\mathrm{RF}, \mathrm{YW}, \mathrm{BK}, \mathrm{KM}$ contributed to interpretation of results and conclusions; RF, $B K$, and KM drafted the manuscript; all authors contributed to manuscript revision. We confirm that the manuscript has been read and approved by all named authors and that there are no other persons who satisfied the criteria for authorship but are not listed. We further confirm that the order of authors listed in the manuscript has been approved by all of us. All authors read and approved the final manuscript.

\section{Funding}

This study has received funding from GlaxoSmithKline and the National Science and Technology Major Project, \#2018ZX10715004. Dr. Meyers is supported by Grant \#UL1TR001866 from the National Center for Advancing Translational Sciences (NCATS), National Institutes of Health (NIH) Clinical and Translational Science Award (CTSA) program. Dr. Kutner is supported by two NIMH grants (T32-MH19139, Behavioral Sciences Research in HIV Infection; Principal Investigator: Theodorus Sandfort, PhD) and the HIV Center for Clinical and Behavioral Studies (P30-MH43520, Principal Investigator: Robert $\mathrm{H}$. Remien, PhD). The funders had no role in study design, data collection and analysis, decision to publish, or preparation of the manuscript.

\section{Availability of data and materials}

The datasets used and/or analysed during the current study are available from the corresponding author on reasonable request.

\section{Ethics approval and consent to participate}

All procedures performed in this study were in accordance with the ethical standards of the Ethics Review Committee of Fudan University, Shanghai, China (IRB00002408 \& FWA00002399) and with the 1964 Helsinki declaration and its later amendments. Written informed consent was obtained from all individual participants included in the study.

\section{Consent for publication}

Not applicable.

\section{Competing interests}

The authors declare that they have no competing interests.

\section{Author details}

${ }^{1}$ Guangzhou Center for Disease Control and Prevention, Guangzhou, China. ${ }^{2}$ HIV Center for Clinical and Behavioral Studies, New York State Psychiatric Institute and Columbia University, New York, USA. ${ }^{3}$ Aaron Diamond AIDS Research Center, The Rockefeller University, 455 1st Avenue, 7th Floor, New York, NY 10016, USA. ${ }^{4}$ Institution of HIV/AIDS, The First Hospital of Changsha, Changsha, China. ${ }^{5}$ School of Public Health, Fudan University, Shanghai, China. ${ }^{6}$ Beijing Youan Hospital, Capital Medical University, Beijing, China. ${ }^{7}$ Shanghai CSW \& MSM Center, Shanghai, China.
Received: 24 July 2019 Accepted: 21 November 2019

Published online: 06 January 2020

\section{References}

1. Pachankis JE, Hatzenbuehler ML, Hickson F, Weatherburn P, Berg RC, Marcus $U$, et al. Hidden from health: structural stigma, sexual orientation concealment, and HIV across 38 countries in the European MSM Internet Survey. AIDS (London, England). 2015;29(10):1239.

2. Qiao S, Zhou G, Li X. Disclosure of same-sex behaviors to health-care providers and uptake of HIV testing for men who have sex with men: a systematic review. Am J Mens Health. 2018;12(5):1197-214.

3. Mayer KH, Bekker L-G, Stall R, Grulich AE, Colfax G, Lama JR. Comprehensive clinical care for men who have sex with men: an integrated approach. Lancet. 2012;380(9839):378-87.

4. Fenway Guide to Lesbian, Gay, Bisexual, and Transgender Health, 2nd Edition. Philadelphia: American College of Physicians; 2015.

5. Wong FY, Huang ZJ, Wang W, He N, Marzzurco J, Frangos S, et al. STIs and HIV among men having sex with men in China: a ticking time bomb? AIDS Edu Prevent. 2009;21(5):430-46.

6. Xu JJ, Tang WM, Zou HC, Mahapatra T, Hu QH, Fu GF, et al. High HIV incidence epidemic among men who have sex with men in China: results from a multi-site cross-sectional study. Infect Dis Poverty. 2016;5(1):82.

7. Ong JJ, Fu H, Pan S, Smith MK, Wu D, Wei C, et al. Missed opportunities for human immunodeficiency virus and syphilis testing among men who have sex with men in China. Sex Transm Dis. 2018;45(6):382-6.

8. Zou H, Meng X, Lu Y, Jia T, Yin H, Luo Z, et al. Delayed HIV testing among men who have sex with men in China is common: Findings from the T2T study. 22nd International AIDS Conference; Amsterdan 2018.

9. Yu L, Ruan Y, Vermund SH, Osborn CY, Wu P, Jia Y, et al. Predictors of antiretroviral therapy initiation: a cross-sectional study among Chinese HIVinfected men who have sex with men. BMC Infect Dis. 2015;15(1):570.

10. Watson J, Tang W, Pan S, Wu D, Zhao P, Cao B, et al. Out of the closet, into the clinic: opportunities for expanding men who have sex with mencompetent Services in China. Sex Transm Dis. 2018;45(8):527-33.

11. Tang W, Mao J, Tang S, Liu C, Mollan K, Cao B, et al. Disclosure of sexual orientation to health professionals in China: results from an online crosssectional study. J Int AIDS Soc. 2017;20(1):21416.

12. WHO. Defining sexual health: report of a technical consultation on sexual health, 28-31 January 2002, Geneva. Geneva; 2006.

13. Tucker JD, Walensky RP, Yang LG, Yang B, Bangsberg DR, Chen XS, et al. Expanding provider-initiated HIV testing at STI clinics in China. AIDS Care. 2012;24(10):1316-9.

14. Askew I, Berer M. The contribution of sexual and reproductive health services to the fight against HIV/AIDS: a review. Reprod Health Matt. 2003; 11(22):51-73.

15. Cheng W, Cai Y, Tang W, Zhong F, Meng G, Gu J, et al. Providing HIVrelated services in China for men who have sex with men. Bull World Health Organ. 2016;94(3):222.

16. Yan H, Zhang R, Wei C, Li J, Xu J, Yang H, et al. A peer-led, communitybased rapid HIV testing intervention among untested men who have sex with men in China: an operational model for expansion of HIV testing and linkage to care. Sex Transm Infect. 2014;90(5):388-93.

17. Li L, Jiang Z, Song W, Ding $Y, X U$ J, He N. Development of HIV infection risk assessment tool for men who have sex with men based on Delphi method. Chin J Epidemiol. 2017;38(10):1426-30.

18. China NBoSo. China statistical yearbook. Beijing: China Statistics Press; 2017.

19. WHO. Classifying health workers. Geneva: WHO; 2010.

20. Neville S, Henrickson M. Perceptions of lesbian, gay and bisexual people of primary healthcare services. J Adv Nurs. 2006;55(4):407-15.

21. Ng BE, Moore D, Michelow W, Hogg R, Gustafson R, Robert W, et al. Relationship between disclosure of same-sex sexual activity to providers, HIV diagnosis and sexual health services for men who have sex with men in Vancouver, Canada. Can J Public Health. 2014;105(3):e186-e91.

22. Eliason MJ, Schope R. Does "don't ask don't tell" apply to health care? Lesbian, gay, and bisexual people's disclosure to health care providers. $J$ Gay Lesbian Med Assoc. 2001;5(4):125-34.

23. Bekker L-G, Alleyne G, Baral S, Cepeda J, Daskalakis D, Dowdy D, et al. Advancing global health and strengthening the HIV response in the era of the sustainable development goals: the international AIDS society — lancet commission. Lancet. 2018;392(10144):312-58. 
24. Marcus JL, Levine K, Grasso C, Krakower DS, Powell V, Bernstein KT, et al. HIV Preexposure prophylaxis as a gateway to primary care. Am J Public Health 2018;108(10):1418-20.

25. Rispel LC, Metcalf CA, Cloete A, Moorman J, Reddy V. You become afraid to tell them that you are gay: health service utilization by men who have sex with men in south African cities. J Public Health Policy. 2011;32(Suppl 1): S137-51.

26. Wei $C$, Raymond HF. Pre-exposure prophylaxis for men who have sex with men in China: challenges for routine implementation. J Int AIDS Soc. 2018; 21(7):e25166.

27. WHO. Guidance on provider-initiated HIV testing and counselling in health facilities. 2007.

28. Jin $\mathrm{X}$, Xiong $\mathrm{R}$, Mao $\mathrm{Y}$. HIV/AIDS cases detection in medical institutions from 2008 to 2013 in China. Zhonghua liu xing bing xue za zhi=. Zhonghua liuxingbingxue zazhi. 2015;36(4):323-6.

\section{Publisher's Note}

Springer Nature remains neutral with regard to jurisdictional claims in published maps and institutional affiliations.

Ready to submit your research? Choose BMC and benefit from:

- fast, convenient online submission

- thorough peer review by experienced researchers in your field

- rapid publication on acceptance

- support for research data, including large and complex data types

- gold Open Access which fosters wider collaboration and increased citations

- maximum visibility for your research: over $100 \mathrm{M}$ website views per year

At BMC, research is always in progress.

Learn more biomedcentral.com/submissions 